\title{
The Knowledge Level of Hospital Staff about Influenza and Pneumococcal Vaccination
}

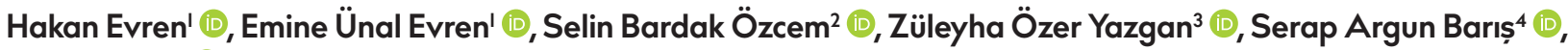 \\ Füsun Yıldız ${ }^{5}$
}

'Department of Infectious Diseases, University of Kyrenia Dr. Suat Günsel Hospital, Kyrenia, Cyprus 2Department of Infectious Diseases, Near East University School of Medicine, Nicosia, Cyprus ${ }^{3}$ Department of Internal Medicine, University of Kyrenia Dr. Suat Günsel Hospital, Kyrenia, Cyprus ${ }^{4}$ Department of Pulmonary Diseases, Kocaeli University School of Medicine, Kocaeli, Turkey

${ }^{5}$ Department of Pulmonary Diseases, University of Kyrenia Dr. Suat Günsel Hospital, Kyrenia, Cyprus

ORCID IDs of the authors: H.E. 0000-000I-8247-8I44; E.Ü.E. 0000-000I-9455-0473; S.B.Ö. 0000-0002-7393-8062; Z.Ö.Y. 0000-00034I70-6205; S.A.B. 0000-0002-4429-944I; F.Y. 0000-0003-48I0-730I

Cite this article as: Evren H, Ünal Evren E, Bardak Özcem S, Özer Yazgan Z, Argun Barıș S, Yıldız F. The Knowledge Level of Hospital Staff about Influenza and Pneumococcal Vaccination. Cyprus J Med Sci 2019; 4(3): 220-4.

\section{BACKGROUND/AIMS}

The aim of this study was to evaluate the knowledge of health care workers (HCW) on the influenza and pneumococcal vaccine.

\section{MATERIALS and METHODS}

A questionnaire about influenza and pneumococcal vaccination was administered to HCW and administrative staff.

RESULTS

A total of 225 subjects were included into the study; there were 180 women $(80 \%)$ and $45(20 \%)$ men. The mean age was $31.9 \pm 11.4$ years, and $73.5 \%$ of the respondents stated that adult vaccination was effective. Pneumococcal vaccination (58.7\%) was less well known, although $86.2 \%$ of respondents indicated that they were familiar with influenza vaccination. Only $28.4 \%$ of respondents indicated that they had influenza vaccine, and none of the cases had a pneumococcal vaccine. In $75 \%$ of influenza-vaccinated participants, the vaccination was suggested by a physician. Among influenza-vaccinated participants, the percentage of people who thought that vaccination was beneficial was $54.4 \%$. The most common reasons for not vaccinating all participants were the belief that vaccination was ineffective (38.7\%) and the belief about not being in a risk group (36.1\%).

\section{CONCLUSION}

It was shown that the rate of influenza vaccination among hospital staff is low, and most of them were not familiar with pneumococcal vaccination. It is thought that educational programs on vaccination should be made to increase the awareness of the hospital staff who are at risk of infection due to their working environment.

Keywords: Health personnel, influenza vaccines, knowledge, pneumococcal vaccines

\section{INTRODUCTION}

Influenza and pneumococcal infections are potential causes of mortality and morbidity for certain high-risk groups, including adults (I). Despite an appropriate treatment, the fatality rates for pneumococcal bacteremia remain high (I5\%$20 \%$ ) in some high-risk adults (2). The incidence of pneumococcal diseases varies seasonally with the incidence of flu. Influenza virus damages epithelial cells of airways and improves the condition for secondary bacterial infection (mostly Streptococcus pneumoniae) (3). In the United States, during the 2014-20I5 flu season, a total of I7,9II patients were hospitalized due to influenza infection with a mortality rate of $9.3 \%$ (4).

Influenza and pneumococcal disease control strategies include immunization of high-risk populations (3). Although the efficacy and effectiveness of influenza and pneumococcal vaccines has been proven, the rate of vaccination remains suboptimal worldwide (5). 
The Center for Disease Control and Prevention (CDC) in the United States reported that the vaccination coverage for influenza in the 2009/20I0 flu season was $41.2 \%$ for all ages and 69.6 for those aged $\geq 64$ years (5). Vaccination coverage of pneumococcal infections is lower than that of influenza among high-risk groups globally. According to a survey from Canada in 2006, $39 \%$ of adults aged $\geq 65$ years received a pneumococcal vaccine, whereas $70 \%$ received influenza vaccine for the same season (6). Health care providers are at high risk of both acquiring and transmitting influenza to patients and other medical staff. It is reported that influenza in health care workers ( $\mathrm{HCW}$ ) can lead to nosocomial outbreaks. Therefore, immunization is recommended for health professionals by the World Health Organization, CDC, and national health authorities of most European countries (7).

The awareness of medical staff about their risk of acquiring influenza and immunization strategies in adults with comorbidities can lead to successful vaccination programs. Consequently, in this study, we aimed to understand the knowledge on influenza and pneumococcal vaccines among HCW.

\section{MATERIALS and METHODS}

A comprehensive search was conducted between September and October 2017 in the study. A self-administered questionnaire was performed for all volunteer hospital staff. Hospital staff included HCW and administrative staff. The HCW included nurses, technicians, and laboratories. Approximately 356 hospital staff were contacted, and 225 of them responded to the questionnaire.

The demographic characteristics (age, gender, duration of working) of participants and the results of the questionnaire were recorded. The questionnaire was prepared by specialists in pulmonary disease and infectious diseases, and it was not a validated questionnaire. It included 10 questions about influenza and pneumococcal vaccines. The knowledge of influenza and pneumococcal vaccines, the effect of the vaccines on reducing the infection risk, vaccination rates among hospital staff, and reasons for refusing the vaccine were examined. The knowledge of vaccination was defined according to the following question: "Do you have knowledge about influenza/pneumococcal vaccine?" The answers were classified as yes, no, or no idea. If the participants were sure about the answer, they chose yes or no, but, if they were not sure about the question, they chose "no idea." For example,

- I am familiar with the name of the vaccine, and I know the efficacy. Yes

- I am not familiar with the name of the vaccine, and I do not know the efficacy. No

- I am familiar with the vaccine, but not with its effectiveness. No idea

All participants were informed about the aim of the study, and they gave written informed consent. The study was approved by the local ethical committee of University of Kyrenia (I0/18/2018, ref no: RY-20I8-II)

\section{Statistical Analysis}

Statistical analyses of the study were performed using the IBM Statistical P ackage for the Social Sciences for Windows version
20.0 (SPSS IBM Corp.; Armonk, NY, USA). Continuous variables were expressed as mean \pm standard deviation, and categorical variables were expressed as counts (percentage). Comparisons of categorical variables between the groups were performed using the chi-square test. A p-value $<0.05$ was considered statistically significant.

\section{RESULTS}

A total of 225 subjects were included in the study; there were 180 women $(80 \%)$ and $45(20 \%)$ men. The mean age of the population was $31.9 \pm 11.4$ years ( $\mathrm{min}, 19 ; \mathrm{max}, 65)$. The mean age was higher in women than men, and the difference was statistically significant $(p=0.001$ ). Nearly $60 \%$ of the hospital staff had been working for at least 5 years. The working area and the duration of working of the participants are shown in Figures I and 2.

Seventy-tree percent of the respondents stated that adult vaccination was effective. There was no statistically significant difference between genders regarding the opinion on the effectiveness of adult vaccination (women: $72.5 \%$; men: $77.8 \%$; $p=0.05$ ). Pneumococcal vaccination (58.7\%) was less well known, although $86.2 \%$ of respondents indicated that they had information about influenza vaccination (Figure 3). Similarly, the level of knowledge about the effect of the pneumococcal vaccine on the reducing risk of infection (40.9\%) was lower than that of influenza vaccination (63.4\%) (Figure 4). The knowledge level

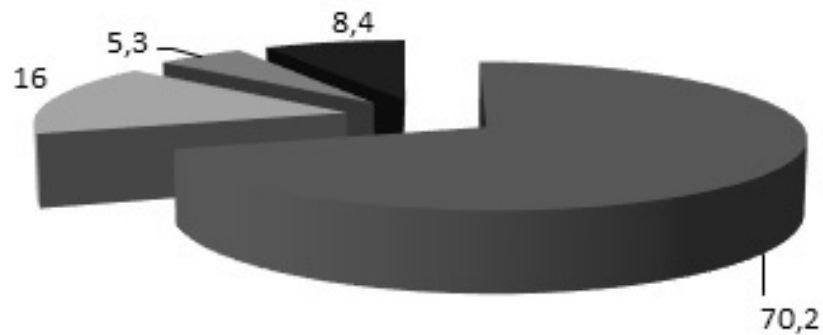

\section{Nurse Technician Laboratories Administrative staff}

\section{Figure I. Distribution of the profession, \%}

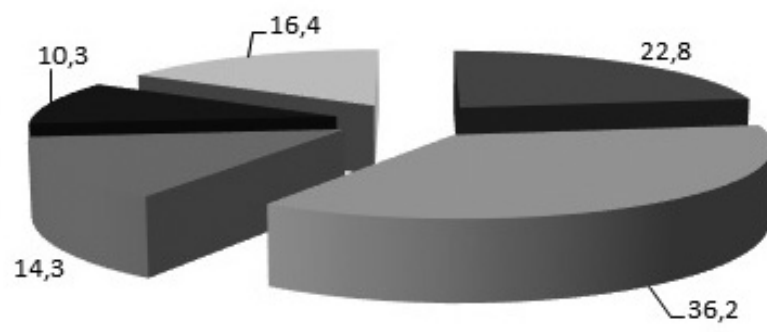

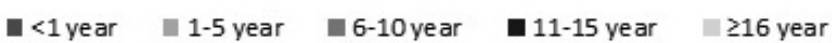


of both influenza and pneumococcal vaccination according to gender are shown in Table I.

Regarding the classification of $\mathrm{HCW}$, the participants who have the working period $\geq 5$ years, the pneumococcal vaccination knowledge level was significantly higher when compared with those with the working period $<5$ years. ( $81.6 \%$ vs. $54 \%$, $p=0.004)$. Influenza and the pneumococcal vaccines were better known to reduce the risk of infection among the HCW who have $a \geq 5$ years working period when compared with those who have a shorter working period ( $81.6 \%$ vs. $59.7 \%, p=0.02$ for influenza vaccine) $(65.8 \%$ vs. $35.8 \%, p=0.003$ for the pneumococcal vaccine). According to the working period, the rate of receiving the influenza vaccine was similar $(p=0.2)$.

Only $28.4 \%$ of respondents indicated that they had influenza vaccine; the rate of women who had influenza vaccination was higher than that of men, but the difference was not significant ( $29.4 \%$ vs. $24.4 \%, p=0.51)$. None of the cases had pneumococcal vaccination. In $75 \%$ of influenza-vaccinated participants, the

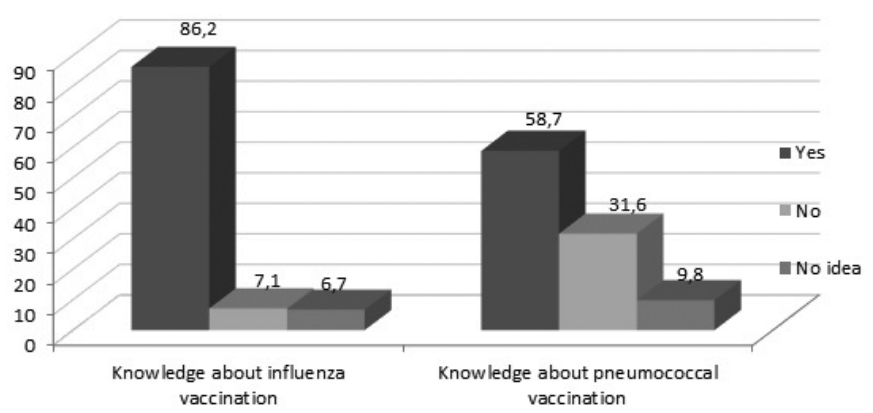

Figure 3. Do you have knowledge about influenza and pneumococcal vaccination? $(\%)$

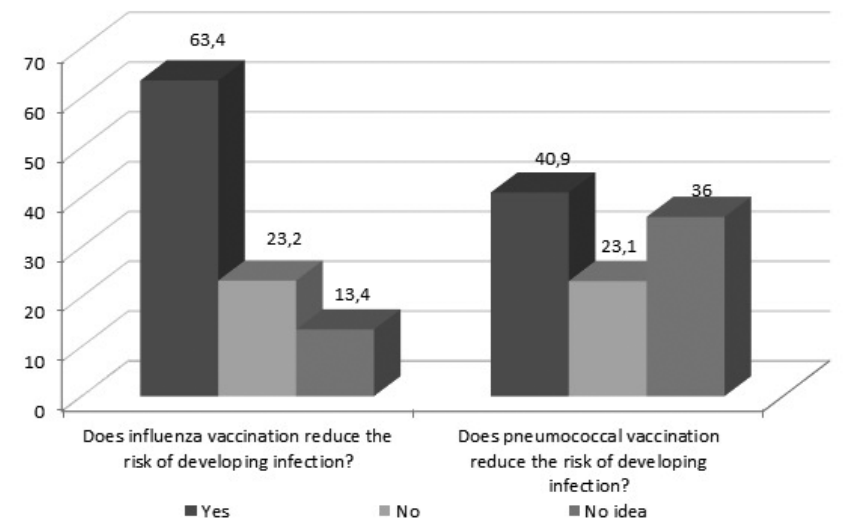

Figure 4. Do vaccines reduce the risk of developing infections? (\%) vaccination proposal was made by a physician. Among influenza-vaccinated participants, the proportion of people who thought that vaccination was beneficial was 54.4\%. However, $33.8 \%$ thought it was not beneficial, and $11.8 \%$ had no idea. Not believing that vaccination was efficient (38.7\%) and the belief about not being in a risk group (36.1\%) were the most common reasons for not vaccinating all participants. In women, the most common reason for not being vaccinated was not believing the efficacy of vaccination, while the belief about not being in risk group was the most common for men (Figure 5).

\section{DISCUSSION}

This study demonstrated that the influenza vaccine was better known than the pneumococcal vaccine ( $86.2 \%$ vs. $58.7 \%$ ). Although the level of knowledge about vaccination was relatively high, the vaccination rates were extremely low among hospital staff. The most common reasons for not vaccinating were the belief that vaccination was inefficient (38.7\%) and the belief about not being in a risk group (36.1\%).

$\mathrm{HCW}$ s have the risk of both acquiring and transmitting influenza. Moreover, every flu season, health care service is disrupted due to the absenteeism of medical staff (7). Therefore, they are an essential target group for influenza vaccination to protect themselves and to prevent transmission to patients (8-10). Annual influenza vaccination for $\mathrm{HCW}$ is recommended in most countries $(\mathrm{II}, 12)$. However, the vaccination coverage of $\mathrm{HCW}$ remains suboptimal worldwide $(13,14)$

Influenza can lead to severe illness and serious complications, such as secondary bacterial pneumonia $(15,16)$. Streptococcus pneumoniae is the most commonly isolated microorganism from adults with pneumonia and sepsis (17). Besides, influenza vaccination plays an indirect role in preventing invasive pneumococcal infection, which tends to occur usually during the flu season (3).

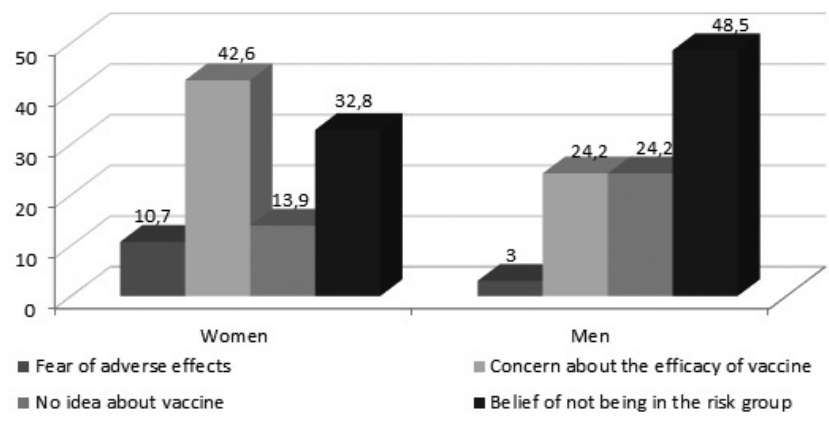

Figure 5. Reasons for not being vaccinated by gender, $\%$

TABLE I. Level of knowledge about influenza and pneumococcal vaccination according to gender

\begin{tabular}{|c|c|c|c|c|c|c|}
\hline & \multicolumn{3}{|c|}{ Women } & \multicolumn{3}{|c|}{ Men } \\
\hline & Yes & No & No idea & Yes & No & No idea \\
\hline Do you have information about influenza vaccination? n(\%) & $157(87.7 \%)$ & $10(5.6 \%)$ & $12(6.7 \%)$ & $36(80 \%)$ & $6(13.3 \%)$ & $3(6.7 \%)$ \\
\hline Do you have information about pneumococcal vaccination? $n(\%)$ & $107(59.4 \%)$ & $57(31.7 \%)$ & $16(8.9 \%)$ & $25(55.6 \%)$ & $14(31.1 \%)$ & $6(13.3 \%)$ \\
\hline Does pneumococcal vaccine reduce the risk of infection? $\mathrm{n}(\%)$ & $75(41.7 \%)$ & $42(23.3 \%)$ & $63(35 \%)$ & $17(37.8 \%)$ & $10(22.2 \%)$ & $18(40 \%)$ \\
\hline
\end{tabular}


In recent years, several studies have been performed to focus on the factors that lead to insufficient adherence to vaccination in Western countries $(18,19)$. Knowledge gaps, fear of side effects, concerns about the efficacy, and the perception of not being in the risk group seem to be the most common reasons to decline vaccination (20).

Studies show that HCWs knowledge of the influenza vaccine is directly correlated with vaccination uptake (2I). It is also reported that getting vaccinated is associated with recommending vaccination to patients. The ratio is $86 \%$ versus $54 \%$ in vaccinated and unvaccinated $\mathrm{HCWs}$ respectively (8).

According to CDC survey, $20 \%$ of persons aged $\geq 65$ years reported they received influenza vaccine, but they said that they never had received the pneumococcal vaccine. Some European countries have reported coverage rates of approximately $50 \%$ for pneumococcal vaccine among the high-risk population. Most countries do not even report these rates. It is shown by some studies that the most important barrier to vaccinating was that most of the high-risk patients were not even aware that the vaccine existed. This study also showed that health care professionals' advice is the most important factor to be vaccinated (2). Health care providers have a critical role in informing patients about vaccination (6). Many studies showed that vaccine provision by an HCW is found to be an independent predictor of the pneumococcal and influenza vaccine uptake in the elderly (22).

In a meta-analysis sponsored by the CDC, HCWs misconceptions about influenza vaccination were similar to those of the general public (23). Another study by Gresser-Edelsburg et al. (24) reported no difference between HCWs and the general public regarding vaccination support.

These data show that the education of HCWs means the education of the public indirectly. The vaccine coverage among HCWs in the United States is $>75 \%$ but is $<30 \%$ in many European countries (25). The mean vaccination coverage rate from 2006 to 2013 flu seasons was $21.6 \%$ ranging from $11 \%$ to $34 \%$ in Italy (26). Some other recent reports show that the influenza vaccination rate among $\mathrm{HCW}$ differs by seasons and country ranging between 50.8\% (Greece 2006-2007) and 35\% (Germany 20I0-20II) (27).

Our study is in the same line with European studies. Although $63.4 \%$ of participants agreed that the influenza vaccine is effective, only $28.4 \%$ of them received the vaccine. None of the participants received the pneumococcal vaccine due to the perception of not being in the risk group. Similarly to our study, Ciftci et al. (28) reported the influenza coverage rate of $26.7 \%$ among $\mathrm{HCWs}$ from Turkey.

In an extensive survey from medical centers in the United States, the most frequent barriers to vaccination were the fear of side effects $39 \%$ and fear of contracting influenza from the vaccine $25 \%$ (29). Among the whole HCW sample in another study from Turkey, the reasons for declining vaccination included the fear of its adverse effects (31\%) and doubts about its efficacy (28.9\%) (27). Another barrier to vaccination was a low perceived risk of influenza infection. Haridi et al. (30) reported that $38.9 \%$ of $\mathrm{HCW}$ decline vaccination due to concerns about efficacy.
Similarly, in our study, $38.7 \%$ of the participants mentioned not to believe in the efficacy of the influenza vaccine, while $36.1 \%$ of them declined due to the perception of not being in the risk group.

Studies indicate that HCWs do not follow recommended immunization practices for adults and themselves. False assumptions and knowledge gaps are the reasons of failing to receive vaccinations. Although the patient and HCWs education is critical in filling knowledge gaps, it has been shown in many studies that knowledge itself is not sufficient to improve immunization practice (27).

Influenza outbreaks in hospitals are related to low vaccination rates among $\mathrm{HCWs}$ (28). These outbreaks put patients at an important risk of acquiring the infection, particularly in critical care units. Health care systems have an ethical and moral duty to protect vulnerable patients from influenza (30).

Due to the failure of voluntary immunization programs, mandatory policies are being increasingly adapted to health care centers. A recent review indicated that a mandatory vaccination strategy is the most successful way to increase vaccination uptake. Many health care centers in the United States have implemented mandatory policies with a nearly $100 \%$ compliance (30).

To the best of knowledge, this is the first study evaluating the knowledge level of hospital staff about influenza and pneumococcal vaccination in Cyprus. However, there are some limitations to the study. The relatively small study population and the use of a non-validated questionnaire were the main limitations. The results of this study may not reflect the knowledge of all hospital staff in the country since it was conducted in only two hospitals in Cyprus. Furthermore, the definition of the knowledge on vaccination depended on only one question.

We found that the influenza vaccine was better known than the pneumococcal vaccine. Although the level of knowledge about vaccination was relatively high, the vaccination rates were meager among hospital staff in Cyprus. These findings should be used to improve any future vaccination campaigns. Raising the awareness accompanied with mandatory policies seem to be likely effective.

Ethics Committee Approval: Ethics committee approval was received for this study from the ethics committee of University of Kyrenia (18/10/2018, ref no: RY-20I8-II).

Informed Consent: Written informed consent was obtained from participants.

Peer-review: Externally peer-reviewed.

Author Contributions: Concept - H.E.; Design - E.Ü.E.; Supervision - F.Y.; Resources - Z.Ö.Y.; Data Collection and/or Processing - S.A.B.; Analysis and/or Interpretation - H.E.; Literature Search - E.Ü.E.; Writing Manuscript - H.E.; Critical Review - F.Y.

Conflict of Interest: The authors have no conflicts of interest to declare.

Financial Disclosure: The authors declared that this study has received no financial support. 


\section{REFERENCES}

I. Ridda I, Lindley IR, Gao Z, Mclntyre P, Macintyre CR. Differences in attitudes, beliefs and knowledge of hospital healthcare workers and community doctors to vaccination of older people. Vaccine 2008; 26(44): 5633-40. [CrossRef]

2. Song JY, Cheong HJ, Heo JY, Noh JY, Seo YB, Kim IS, et al. Outpatient-Based Pneumococcal Vaccine Campaign and Survey of Perceptions about Pneumococcal Vaccination in Patients and Doctors. Yonsei Med J 2013; 54(2): 469-75. [CrossRef]

3. Gilchrist SA, Nanni A, Levine O. Benefits and Effectiveness of Administering Pneumococcal Polysaccharide Vaccine With Seasonal Influenza Vaccine: An Approach for Policy makers. Am J Public Health 2012; 102(4): 596-605. [CrossRef]

4. Appiah GD, Blanton L, D'Mello T, Kniss K, Smith S, Mustaquim D, et al. Influenza activity -United States, 20l4-15 season and composition of the 2015-16 influenza vaccine. MMWR Morb Mortal Wkly Rep 2015; 64(21): 583-90.

5. Satman I, Akalin S, Cakir B, Altinel S, Study Group T diaVAX. The effect of physicians' awareness on influenza and pneumococcal vaccination rates and correlates of vaccination in patients with diabetes in Turkey: An epidemiological Study "diaVAX." Hum Vaccin Immunother 2013; 9(12): 2618-26. [CrossRef]

6. Schneeberg A, Bettinger JA, McNeil S, Ward BJ, Dionne M, Cooper $C$, et al. Knowledge, attitudes, beliefs and behaviours of older adults about pneumococcal immunization, a Public Health Agency of Canada/Canadian Institutes of Health Research Influenza Research Network (PCIRN) investigation. BMC Public Health 2014; 14: 442. [CrossRef]

7. Durando P, Alicino C, Dini G, Barberis I, Bagnasco AM, ludici R, et al. Determinants of adherence to seasonal influenza vaccination among healthcare workers from an Italian region: results from a cross-sectional study. BMJ Open 2016; 6(5): e0I0779. [CrossRef]

8. Nutman A, Yoeli N. Influenza vaccination motivators among healthcare personnel in a large acute care hospital in Israel. Isr J Health Policy Res 2016; 5: 52. [CrossRef]

9. World Health Organization. Weekly Epidemiological Record (WER) Geneva: World Health Organization; 2012. WHO position paper on influenza vaccines - November 2012; pp. 46I-76.

10. Wilde JA, McMillan JA, Serwint J, Butta J, O'Riordan MA, Steinhoff $M C$. Effectiveness of influenza vaccine in healthcare professionals: a randomized trial. JAMA 1999; 28I(I0): 908-13. [CrossRef]

II. Lorenc T, Marshall D, Wright K, Sutcliffe K, Sowden A. Seasonal influenza vaccination of healthcare workers: systematic review of qualitative evidence. BMC Health Serv Res 2017; 17(I): 732. [CrossRef]

12. Maltezou HC, Poland GA. Vaccination policies for healthcare workers in Europe. Vaccine 2014; 32(38): 4876-80. [CrossRef]

13. Kassianos $G$. Willingness of European healthcare workers to undergo vaccination against seasonal influenza: current situation and suggestions for improvement. Drugs Context 2015; 4: 212268. [CrossRef]

14. Heinrich-Morrison K, McLellan S, McGinnes U, Carroll B, Watson K, Bass $P$, et al. An effective strategy for influenza vaccination of healthcare workers in Australia: experience at a large health service without a mandatory policy. BMC Infect Dis 2015; 15: 42. [CrossRef]

15. Fiore AE, Shay DK, Broder K, Iskander JK, Uyeki TM, Mootrey G, et al. Centers for Disease Control and Prevention (CDC). Prevention and control of influenza with vaccines: recommendations of the Advisory Committee on Immunization Practices (ACIP). MMWR Recomm Rep 2009; 58(RR-8): I-52.

16. Brundage JF, Shanks GD. Deaths from bacterial pneumonia during 1918 19 influenza pandemic. Emerg Infect Dis 2008; 14(8): 1193-9. [CrossRef]

17. Bryant KA, Stover B, Cain L, Levine GL, Siegel J, Jarvis WR. Improving influenza immunization rates among healthcare workers caring for high-risk pediatric patients. Infect Control Hosp Epidemiol 2004; 25: 912-7. [CrossRef]

18. Bellia C, Setbon M, Zylberman P, Flahault A. Healthcare worker compliance with seasonal and pandemic influenza vaccination. Influenza Other Respir Viruses 2013; 7(Suppl 2): 97-I04. [CrossRef]

19. Barbadoro P, Marigliano A, Di Tondo E, Chiatti C, Di Stanislao F, D'Errico MM, et al. Determinants of influenza vaccination uptake among Italian healthcare workers. Hum Vaccin Immunother 2013; 9 : 911-6. [CrossRef]

20. Hollmeyer HG, Hayden F, Poland G, Buchholz U. Influenza vaccination of healthcare workers in hospitals--a review of studies on attitudes and predictors. Vaccine 2009; 27: 3935-44. [CrossRef]

21. Martinello RA, Jones L, Topal JE. Correlation between healthcare workers' knowledge of influenza vaccine and vaccine receipt. Infect Control Hosp Epidemiol 2003; 24(II): 845-7. [CrossRef]

22. Nichol KL, Mac Donald R, Hauge M. Factors associated with influenza and pneumococcal vaccination behavior among high-risk adults. J Gen Intern Med 1996; II(II): 673-7. [CrossRef]

23. Nowak GJ, Sheedy K, Bursey K, Smith TM, Basket M. Promoting influenza vaccination: insights from a qualitative meta-analysis of 14 years of influenza-related communications research by U.S. Centers for Disease Control and Prevention (CDC). Vaccine 20I5; 33(24): 2741-56. [CrossRef]

24. Gesser-Edelsburg A, Walter N, Green MS. Healthcare workers- part of the system or part of the public? Ambivalent risk perception in healthcare workers. Am J Infect Control 20l4; 42(8): 829-33. [CrossRef]

25. Black $C L$, Yue $X$, Ball SW, Donahue SMA, Izrael D, de Perio MA, ef al. Influenza vaccination coverage among healthcare personnel United States, 2014-15 influenza season. MMWR Morb Mortal Wkly Rep 2015; 64(36): 993-9. [CrossRef]

26. Alicino C, ludici R, Barberis I, Paganino C, Cacciani R, Zacconi M, et al. Influenza vaccination among healthcare workers in Italy: the experience of a large tertiary acute-care teaching hospital. Hum Vaccin Immunother 2015; II(I): 95-100. [CrossRef]

27. Johnson DR, Nichol KL, Lipczynski K. Barriers to adult immunization. Am J Med 2008; I2I(7 Suppl 2): S28-35. [CrossRef]

28. Ciftci F, Sen E, Demir N, Ciftci O, Erol S, Kayacan O. Beliefs, attitudes, and activities of healthcare personnel about influenza and pneumococcal vaccines. Hum. Vaccin Immunother 2018; 14(I): III-7. [CrossRef]

29. Hollmeyer $\mathrm{H}$, Hayden F, Mounts A, Buchholz U. Review: interventions to increase influenza vaccination among healthcare workers in hospitals. Influenza Other Respir Viruses 2013; 7(4): 604-2I. [CrossRef]

30. Haridi HK, Salman KA, Basaif EA, Al-Skaibi DK. Influenza vaccine uptake, determinants, motivators, and barriers of the vaccine receipt among healthcare workers in a tertiary care hospital in Saudi Arabia. J Hosp Infect 2017; 96(3): 268-75. [CrossRef] 